This document is confidential and is proprietary to the American Chemical Society and its authors. Do not copy or disclose without written permission. If you have received this item in error, notify the sender and delete all copies.

\title{
Promoted Exchange Reaction Between Alkanethiolate Self- Assembled Monolayers and an Azide-Bearing Substituent
}

\begin{tabular}{|r|l|}
\hline Journal: & The Journal of Physical Chemistry \\
\hline Manuscript ID & jp-2016-09565z.R1 \\
\hline Manuscript Type: & Article \\
\hline Date Submitted by the Author: & 21-Oct-2016 \\
\hline Complete List of Authors: & $\begin{array}{l}\text { Yan, Rui; Heidelberg University, Applied Physical Chemistry } \\
\text { Le Pleux, Loïc; Centre National de Recherche Scientifique, CEISAM } \\
\text { Mayor, Marcel; University of Basel, Department of Chemistry } \\
\text { Zharnikov, Michael; Universität Heidelberg, Angewandte Physikalische } \\
\text { Chemie }\end{array}$ \\
\hline
\end{tabular}




\title{
Promoted Exchange Reaction Between Alkanethiolate Self-Assembled Monolayers and an Azide-Bearing Substituent
}

\author{
Rui Yan, ${ }^{1}$ Loïc Le Pleux, ${ }^{2}$ Marcel Mayor, ${ }^{2,3}$ and Michael Zharnikov ${ }^{1 *}$ \\ ${ }^{1}$ Applied Physical Chemistry, Heidelberg University, Im Neuenheimer Feld 253, 69120 \\ Heidelberg, Germany \\ ${ }^{2}$ University of Basel, Department of Chemistry, St. Johannsring 19, CH-4056 Basel, \\ Switzerland \\ ${ }^{3}$ Forschungszentrum Karlsruhe GmbH, Institute for Nanotechnology, P. O. Box 3640, 76021 \\ Karlsruhe, Germany
}

13

15

16

18

19

20

21

22

24

25

26

27

28

29

30

31

32

33

34

35

36

37

38

39

40

41

42

43

44

45

46

47

48

49

50

51

52

53

54

55

56

57

58

59

60 


\begin{abstract}
The possibility of ultraviolet (UV) light promoted exchange reaction (UVPER) between the primary alkanethiolate (AT) self-assembled monolayers (SAM) and an azide-functionalized substituent (12-Azido-1-dodecanethiol, C12N3), capable of click reaction with ethynyl-bearing species, is demonstrated. This reaction resulted in the mixed AT/C12N3 films, with the portion of $\mathrm{C} 12 \mathrm{~N} 3$ precisely controlled by selection of a suitable UV dose. As the primary matrix, either non-substituted or oligo(ethylene glucole) (OEG) substituted AT SAMs were used, targeting mixed SAMs of chemical and biological significance. To demonstrate the flexibility of the approach, UV light with two different wavelengths (254 and $375 \mathrm{~nm}$ ) was used, applied to the non-substituted and OEG-substituted AT SAMs, respectively. The surface density of the chemically active azide groups embedded in the non-reactive primary matrix could be varied according to the composition of the mixed SAMs, as demonstrated by the subsequent click reaction between these SAMs and several representative functional moieties bearing a suitable group for the click reaction with azide. For the OEG-AT/C12N3 films, this resulted in the preparation of templates for specific protein adsorption, comprising biotin-bearing moieties embedded in the protein-repelling OEG-AT matrix. The density of the biotin receptors was varied according to the density of the $\mathrm{C} 12 \mathrm{~N} 3$ moieties. The templates exhibited much higher affinity to the specific protein (avidin) as compared to a non-specific one. The surface density of avidin could be varied in accordance with the density of the biotin receptors, i.e. directly controlled by the UV dose within the UVPER procedure. The entire approach was extended to lithography, relying on a commercial maskless UV lithography setup. Representative gradient patterns of specifically attached avidin in the protein-repelling OEG-AT matrix were fabricated.
\end{abstract}




\section{Introduction}

Self-assembled monolayers (SAMs) have since long become a valuable part of modern nanotechnology. ${ }^{1-3}$ One of the major advantages of these systems is the possibility of precise control of chemical composition of surfaces and interfaces. This is generally achieved by selection of a proper terminal tail group which, provided a contamination-free character and a dense molecular packing of the monolayer, comprises the SAM-ambient interface, redefining the chemical properties of the entire system. The family of potential tail groups is very broad, ranging from small moieties such as methyl or hydroxyl to larger species of electrochemical (e.g., ferrocene), nanothechnological (e.g., azobenzene) or biological (e.g., biotin) significance. $^{3}$

Along with one-component SAMs bearing a specific tail group, mixed monolayers comprising of molecules with different tail groups can be formed. Such monolayers have several advantages as compared to the single-component films. First, the variety of possible chemistries can be significantly extended. Second, chemical composition of the SAM-ambient interface can be precisely tuned to achieve a particular property or to serve a particular application. Third, the surface density of a particular tail group can be precisely varied, with the second tail group serving as a passive matrix.

The most popular way to prepare mixed monolayer is coadsorption, starting from a mixed solution of both SAM precursors within the standard immersion procedure. The resulting surface composition can, however, differ noticeably or even drastically from the solution composition. An even more important constraint is a possible phase separation in the mixed SAMs, following a thermodynamical drive for aggregation of similar species. Such a phase separation can affect the properties of the mixed films, especially at the nanoscale, resulting in failing performance of the entire system. An alternative approach is a backfilling procedure, starting from a low-density film of one component and filling the residual space with the second component, until a dense molecular film is formed. This procedure can, however, be only applied to certain molecular precursors, differing significantly in their SAM building ability. Finally, there is a substitution procedure, relying on the substitution reaction between the primary, single-component monolayer and a second SAM precursor bearing a different tail 
group. Such a procedure works, however, for certain combinations of molecules only. In addition, the substitution reaction can take very long and occur to a limited extent only.

Recently, we have suggested a way to avoid the limitations of the standard substitution reaction promoting it by electron irradiation of the primary, single-component SAM or by its exposure to ultraviolet (UV) light. ${ }^{4-8}$ Such a pretreatment creates subtle defects in the primary monolayer, which, subsequently, enables effective exchange reaction between the defect-affected molecules in the primary film and potential substituents in solution. As a result, the kinetics of the substitution process can be significantly accelerated and the composition of the resulting mixed SAMs can be varied in a broad range by adjusting either irradiation dose or duration of the exchange reaction. ${ }^{5}$ Limitations related to the specific SAM precursors can be released as well, so that a very broad variety of different molecules can be mixed, starting, most frequently, from a primary SAM of non-substituted or specifically substituted alkanethiolates (AT) on gold. Finally, the promoted exchange reaction can be applied lithographically, resulting in quite sophisticated chemical and biological patterns. ${ }^{9,10}$

A useful extension of the above approach can be a use of a substituent bearing a tail group capable of further modification of subsequent attachment chemistry. A perspective group in this regard is azide $\left(-\mathrm{N}=\mathrm{N}^{+}=\mathrm{N}^{-}\right)$which is capable of click reaction with ethynyl, enabling attachment of a broad variety of species having the respective substitution. ${ }^{11-16}$ Accordingly, in the present study we tested the possibility to use azide-substituted ATs as substituents in promoted exchange reaction. As primary matrix we utilized either non-substituted or oligo(ethylene glucole) (OEG) substituted ATs, targeting mixed SAMs of chemical and biological significance. It is well-known that properly designed OEG substituted monolayers exhibit pronounced protein-repelling properties, building therefore an ideal, biologically-inert matrix for specific biological receptors. ${ }^{17-22}$ As a promoting tool for the substitution reaction we used UV light which has several essential advantages over electron irradiation since the exposure of SAMs to UV light does not require vacuum and can be performed under standard laboratory conditions $\mathrm{s}^{7,23,24}$ and even in solution ${ }^{25}$.

To demonstrate the flexibility of the approach we used the light with two different wavelengths, viz. $254 \mathrm{~nm}$ and $375 \mathrm{~nm}$, applying it to the non-substituted and OEG-substituted 
AT SAMs, respectively. As shown in our previous studies, ${ }^{7,23}$ UV light can be applied in a broad wavelength range within the UVPER approach but the efficiency of this reaction decreases significantly with increasing wavelength of UV light, following the behavior of the cross-sections of the UV induced damage. Consequently, a major advantage of UVPER at 254 $\mathrm{nm}$ is its high efficiency while UV light with a longer wavelength has more potential for lithography, in particular because of the availability of respective, commercial lithographic setups. Note, however, that UV lithography with SAM-like resists and templates can be performed at shorter wavelengths as well but requires quite sophisticated, custom-designed experimental setups. ${ }^{26-28}$

\section{Experimental}

Materials and Chemicals. All solvents were purchased from Sigma-Aldrich and used as received. The SAM precursors used in this study, viz. $\mathrm{HS}-\left(\mathrm{C}_{2} \mathrm{H}_{2}\right)_{11}-\mathrm{CH}_{3}$ (C12), HS- $\left(\mathrm{CH}_{2}\right)_{11}\left(\mathrm{OCH}_{2} \mathrm{CH}_{2}\right)_{\mathrm{n}}-\mathrm{OH}(\mathrm{EGn} ; \mathrm{n}=3$ and 6), and 12-Azido-1-dodecanethiol (C12N3) are shown in Schema 1. The C12 and EGn compounds were purchased from Sigma-Aldrich and ProChimia Surfaces, respectively, and used as received. The C12N3 compound was custom-synthesized. The description of the syntheses procedure and the respective spectroscopic data be found in the Supporting Information.

The gold substrates were purchased from Georg Albert PVD-Beschichtungen and used as received. They were prepared by thermal evaporation of gold (30-100 nm thickness, 99.99\% purity) onto polished single-crystal silicon (100) wafers (Silicon Sense) that had been precoated with a $5 \mathrm{~nm}$ titanium adhesion layer. The films were polycrystalline, exposing preferably (111) orientated surfaces of individual crystallites.

The compounds for the click reaction included 1-ethynyl-3,5-bis(trifluoromethyl)benzene (EFB, 630241), dibenzocyclooctyne-PEG4-biotin conjugate (DBPB), and biotin-PEG4-alkyne (BPA). These compounds were purchased from Sigma-Aldrich and are shown in Schema 2. Further compounds and biomolecules used in this study include (+)-sodium L-ascorbate (A7631) and copper(II) sulfate pentahydrate (209198), avidin (A9275), and bovine serum albumin (BSA, A7638). All these compounds were purchased from Sigma-Aldrich. 
SAM Preparation. The primary SAMs were fabricated by immersion of the freshly prepared substrates in $1 \mathrm{mmol}$ solutions of either C12 or EGn compounds in absolute ethanol for $24 \mathrm{~h}$ at room temperature. After immersion, the films were rinsed with ethanol and blown dry with argon. Extensive characterization showed no evidence of impurities or oxidative degradation products.

General Comments: The entire procedure, including UV irradiation, promoted exchange reaction, subsequent click reaction, and attachment of proteins (for the EGn case only) is illustrated in Figure 1. The fabricated films were characterized by contact angle goniometry, X-ray photoelectron spectroscopy (XPS), and near-edge fine structure absorption (NEXAFS) spectroscopy. The fabricated protein patterns (see below) were imaged by secondary electron microscopy (SEM).

UV-Irradiation: The UV irradiation treatment was performed under ambient conditions. UV light with two different wavelengths, viz. 254 and $375 \mathrm{~nm}$, was used, applied to the $\mathrm{C} 12$ and EGn films, respectively. The $254 \mathrm{~nm}$ light was provided by short-wave (UVC) $\mathrm{Hg}$ vapor lamps (Benda Konrad Laborgeräte). The $375 \mathrm{~nm}$ light was provided by a combination of the V4100 - DLP DiscoveryTM Production Bundles and the High-power UV LED Optical Module for DLP DiscoveryTM 0.7 XGA DMD purchased from Texas Instruments Inc. via ViALUX GmbH, Germany. The DMD chip contains $1024 \times 768$ individually controlled micromirrors, with $13.6 \mu \mathrm{m}$ pitch. The high power UV LED Optical Module consists of a 10 W UV LED source $(375 \mathrm{~nm})$ with the respective illumination and projection optics. The LED source was operated at $80 \%$ power. See ref 24 for details of this experimental setup.

Along with homogeneous irradiation, the DLP setup was used to fabricate lithographic patterns. The patterns were designed with Microsoft Paint and fed as JPEG files to the DMD controller.

Exchange Reaction. The pristine and UV-light-treated C12 and EGn SAMs were immersed into $1 \mathrm{mg} / \mathrm{ml} \mathrm{C} 12 \mathrm{~N} 3$ solution in ethanol for $2 \mathrm{~h}$. After immersion, the films were rinsed with ethanol and blown dry with argon.

Click Reaction. Click reaction was performed in either catalyst-mediated or catalyst-free fashion. $\mathrm{CuSO}_{4}$ was reduced by sodium ascorbate at $\mathrm{RT}$ to get $\mathrm{Cu}^{+}$as catalyst. Subsequently, 
the $\mathrm{C} 12 / \mathrm{C} 12 \mathrm{~N} 3$ films were immersed into mixed solution of $\mathrm{Cu}^{+}$and EFB at RT for 72h. Similarly, the EGn/C12N3 films were immersed into mixed solution of $\mathrm{Cu}^{+}$and BPA at RT for $72 \mathrm{~h}$ (catalyst-mediated click reaction). In addition, catalyst-free click reaction was performed, by immersing the EGn/C12N3 films into solution of DBPB at RT for $72 \mathrm{~h}$. The results of the latter reaction are described in detail, while the results of the catalyst-mediated click reaction with BPA, which was efficient as well, will be presented elsewhere.

Protein Adsorption. BSA and avidin were used to test non-specific and specific protein affinity of the DBPB- and BPA-functionalized EGn/C12N3 templates. The protein adsorption was carried out from a $0.1 \mathrm{mg} / \mathrm{ml}$ solution of the respective protein in $\mathrm{PBS}\left(\mathrm{pH}=7.4\right.$ at $25^{\circ} \mathrm{C}$ ). The samples were washed in Millipore water and dried under argon flow.

Contact Angle Goniometry. The single-component and mixed monolayers were characterized by contact angle goniometry. Advancing contact angles of Millipore water were measured on freshly prepared samples with a Kruss goniometer Model G1. The measurements were performed under ambient conditions with the needle tip in contact with the drop. The drop volume was about $2 \mu \mathrm{L}$. At least three measurements at different locations on each sample were made. The averaged values are reported. Deviations from the average were less than $2^{\circ}$.

XPS. For the XPS characterization, a dedicated spectrometer (MAX200, Leybold-Heraeus) equipped with an Mg Ka X-ray source (1253.6 eV; $200 \mathrm{~W}$ ) and a hemispherical analyser was used. The X-ray source was positioned $\sim 1.5 \mathrm{~cm}$ away from the sample. The spectra were recorded in normal emission geometry with an energy resolution of $\sim 0.9 \mathrm{eV}$. The recorded spectra were divided by the spectrometer transmission function and the binding energy $(\mathrm{BE})$ scale was referenced to the $\mathrm{Au} 4 \mathrm{f}_{7 / 2}$ peak of clean gold at $84.0 \mathrm{eV}^{29}$ Apart from the characterization of the SAMs, XPS was also used to monitor the protein adsorption, which was performed on the basis of the characteristic $\mathrm{N}$ 1s signal following the methodology of our previous publications. ${ }^{7,8,23}$

NEXAFS Spectroscopy. NEXAFS spectroscopy measurements were performed at the bending magnet HE-SGM beamline of the synchrotron storage ring BESSY II (Helmloltz-Zentrum-Berlin). A dedicated experimental station was used. ${ }^{30}$ The spectra acquisition was carried out at the carbon and nitrogen K-edges in the partial electron yield 
(PEY) mode with retarding voltages of $-150 \mathrm{~V}$ and $-300 \mathrm{~V}$, respectively. As the primary X-ray source, linearly polarized synchrotron light with a polarization factor of $\sim 91 \%$ was used. The incidence angle of the X-rays was varied in some cases following the standard approach. ${ }^{31}$ The energy resolution was $\sim 0.3 \mathrm{eV}$ at the $\mathrm{C}$ K-edge and $\sim 0.5 \mathrm{eV}$ at the $\mathrm{N}$ K-edge. The photon energy (PE) scale was referenced to the pronounced $\pi^{*}$ resonance of highly oriented pyrolytic graphite at $285.38 \mathrm{eV}^{32}$ Raw C-K-edge NEXAFS spectra were normalized to the incident photon flux by division through a spectrum of a clean, freshly sputtered gold sample. Subsequently, these spectra were reduced to the standard form by subtracting a linear pre-edge background and normalizing to the unity edge jump (determined by a nearly horizontal plateau 40-50 eV above the respective absorption edges). The $\mathrm{N}$ K-edge spectra are presented as measured, after a suitable normalization procedure.

SEM. The fabricated protein patterns were imaged using a Leo 1530 Gemini SEM device (Zeiss, Germany). The images were recorded at an acceleration voltage of $5 \mathrm{kV}$. The residual gas pressure was ca. $5 \times 10^{-6}$ mbar.

\section{Results and Discussion}

\subsection{C12/C12N3 Monolayers}

The results of UVPER for the C12 templates were monitored by contact angle goniometry, XPS, and NEXAFS spectroscopy. Advancing water contact angle and derived portion of C12N3 for the C12/C12N3 SAMs fabricated by UVPER (step 1 in Figure 1a) are presented in Figure 2 as functions of UV dose. The portion of C12N3 was calculated according to the Cassie law, viz. $\cos \theta_{M}=f \cos \theta_{1}+(1-f) \cos \theta_{2}$, where $\theta_{M}$ is the contact angle of the mixed $\mathrm{C} 12 / \mathrm{C} 12 \mathrm{~N} 3$ monolayer and $\theta_{1}$ and $\theta_{2}$ are the contact angles of the reference, single-component C12N3 and C12 SAMs, respectively. The latter values were estimated at $71^{\circ}$ $(\mathrm{C} 12 \mathrm{~N} 3)$ and $110^{\circ}(\mathrm{C} 12)$. According to Figure 2, the contact angle decreases gradually with the increasing UV dose, manifesting the efficient exchange reaction with the extent controlled by the dose. According to the evaluation, the portion of $\mathrm{C} 12 \mathrm{~N} 3$ in the $\mathrm{C} 12 / \mathrm{C} 12 \mathrm{~N} 3$ monolayers can be varied from $\sim 20 \%$ to $\sim 90 \%$ upon the dose variation from 0 to $10 \mathrm{~J} / \mathrm{cm}^{2}$. Significantly, the exchange reaction occurs to some extent even without UV irradiation (at the given 
conditions), which limits slightly the dynamical range of UVPER and diminishes contrast of potential chemical patterns prepared by UVPER based lithography.

The above results were supported by the XPS data. The N 1s XPS spectra of the C12 SAMs after the non-promoted and promoted exchange reaction with $\mathrm{C} 12 \mathrm{~N} 3$ are shown in Figure 3 for several selected doses, along with the spectrum of the single-component $\mathrm{C} 12 \mathrm{~N} 3$ monolayer taken as a reference. The latter spectrum exhibits characteristic emissions of the azide group at BEs of 400.7 and $404.1 \mathrm{eV}$, corresponding to the nitrogen atoms within the azide group which are richer and poorer in electrons. ${ }^{12,16,33}$ The spectrum agrees well with the literature data, ${ }^{34}$ including the intensity relation between the both components, and exhibits no trace of X-ray induced damage, which is of particular importance for azide-containing systems because of their sensitivity to ionizing radiation. ${ }^{34}$ The spectra of the films prepared by UVPER exhibit the same emission structure, establishing the formation of mixed $\mathrm{C} 12 / \mathrm{C} 12 \mathrm{~N} 3$ monolayers and intact character of the azide groups in these films. The intensity of the characteristic emissions increases with increasing dose, in accordance with the data in Figure 2, establishing once more that the portion of $\mathrm{C} 12 \mathrm{~N} 3$ in the mixed C12/C12N3 SAMs can be precisely controlled by UV dose. The spectrum of the film prepared by non-promoted exchange reaction $\left(0 \mathrm{~J} / \mathrm{cm}^{2}\right)$ exhibits no characteristic features of the azide group. This can be, however, related to the noisy character of this spectra associated with the comparably low photoionization cross-section of nitrogen and the limited time for the spectra acquisition. Consequently, a certain extent of non-promoted exchange reaction cannot be excluded, above all in view of the contact angle data (Figure 2).

The NEXAFS data for the C12 SAMs after promoted (variable dose) exchange reaction with $\mathrm{C} 12 \mathrm{~N} 3$ are presented in Figure 4, along with the spectra of the single-component C12N3 and C12 monolayers taken as references. Two kinds of spectra are shown, viz. the spectra acquired at an X-ray incidence angle of $55^{\circ}$, which are exclusively representative of the electronic structure of the films, and the difference between the spectra collected under the normal $\left(90^{\circ}\right)$ and grazing $\left(20^{\circ}\right)$ incidence geometry, which is representative of the molecular orientation in the monolayers. ${ }^{31}$ The $\mathrm{C}$ K-edge spectrum of the single-component C12 SAM in Figure $4 \mathrm{a}$ exhibits the characteristic absorption resonances of alkyl chain, viz. a most prominent feature at $\sim 287.7 \mathrm{eV}$ (1) associated frequently with predominantly Rydberg states ${ }^{35}$ 
(see ref 5 for a discussion regarding the alternative assignments) as well as two broader resonances at $\sim 293.4 \mathrm{eV}(2)$ and $\sim 301.6 \mathrm{eV}(3)$ related to valence, antibonding $\mathrm{C}-\mathrm{C} \sigma^{*}$ and $\mathrm{C}-\mathrm{C}^{\prime} \sigma^{*}$ orbitals, respectively. These resonances exhibit pronounced linear dichroism, i.e. intensity dependence on X-ray incidence angle, as evidenced by the appearance of the intense peaks at the positions of these resonances in the difference spectra in Figure 4c. This suggests, as expected, a high orientational order in the $\mathrm{C} 12$ monolayers, with an upright orientation of the molecular chains, as follows from the specific signs of the difference peaks in the $90^{\circ}-20^{\circ}$ spectra. ${ }^{5}$

The C K-edge spectra of the single-component C12N3 SAMs and the monolayers prepared by UVPER exhibit the same absorption structure as in the C12/Au case (Figure 4a), corresponding to the aliphatic backbone. The $90^{\circ}-20^{\circ}$ spectra of these films exhibit pronounced linear dichroism, with the similar signs of the difference peaks as for $\mathrm{C} 12 / \mathrm{Au}$ (Figure 4c). This suggests that (i) azide substitution does not result in significant disordering of the resulting AT monolayers and (ii) the molecular order is still persistent upon the mixture of $\mathrm{C} 12$ and $\mathrm{C} 12 \mathrm{~N} 3$. Note, however, that the lower intensities of the difference peaks in the spectra of $\mathrm{C} 12 \mathrm{~N} 3$ and $\mathrm{C} 12 / \mathrm{C} 12 \mathrm{~N} 3$ SAMs suggest a low extent of the orientational order in these systems as compared to $\mathrm{C} 12 / \mathrm{Au}$. This is expectable since an $\omega$-substitution usually has such an effect $(\mathrm{C} 12 \mathrm{~N} 3 / \mathrm{Au})$ and the mixing can be associated with a certain degree of disorder (C12/C12N3 SAMs). ${ }^{5}$ Quantitative evaluation of the C K-edge NEXAFS data within the standard procedure, ${ }^{31,36}$ relying on the intensity of the $\mathrm{R}^{*}$ resonance, gives average tilt angles of the alkyl backbones of $34^{\circ}, 37^{\circ}, 40^{\circ}$, and $37^{\circ}$ for $\mathrm{C} 12 / \mathrm{Au}, \mathrm{C} 12 \mathrm{~N} 3 / \mathrm{Au}$ and $\mathrm{C} 12 / \mathrm{C} 12 \mathrm{~N} 3$ SAMs prepared at 5 and $10 \mathrm{~J} / \mathrm{cm}^{2}$, respectively (with a standard accuracy of such an evaluation, $\pm 3^{\circ}$ ). The former value is very close to the literature one ${ }^{37,38}$ while the latter values are only slightly higher, supporting the above conclusion regarding a minor effect of the azide substitution on the molecular orientation and establishing that the orientational order of the $\mathrm{C} 12 / \mathrm{C} 12 \mathrm{~N} 3 \mathrm{SAMs}$ is close to that of $\mathrm{C} 12 \mathrm{~N} 3 / \mathrm{Au}$.

The N K-edge spectrum of the single-component C12N3 SAM in Figure 4c exhibits the characteristic absorption resonances of the azide group at photon energies of $399.7 \mathrm{eV}$ (1), $400.9 \mathrm{eV}(\mathbf{2}), 402.6 \mathrm{eV}(3)$, and $404.0 \mathrm{eV}$ (4). Both the positions of these resonances and their relative intensities agree well with the previous work. ${ }^{39}$ The two former resonances (1 and $\left.\mathbf{2}\right)$ 
are associated with the terminal nitrogen atoms of the azide group and correspond to electron transitions from the $\mathrm{N}$ 1s state to two different $\pi^{*}$ orbitals. ${ }^{39}$ The two latter resonances $(3$ and 4) are related to the positively charged, middle nitrogen atom of the azide group and correspond to electron transitions from the respective $\mathrm{N} 1 \mathrm{~s}$ state to two different $\pi^{*}$ orbitals. ${ }^{39}$ Similar to the C K-edge case, the N K-edge spectra of C12N3/Au exhibit pronounced linear dichroism (Figure 4d), suggesting that the azide groups at the SAM-ambient interface are well ordered. The positive sign of the $\pi^{*}$ difference peaks in the $90^{\circ}-20^{\circ}$ spectrum of $\mathrm{C} 12 \mathrm{~N} 3 / \mathrm{Au}$ suggests an upright orientation of the azide groups, in view of the perpendicular orientation of the $\pi^{*}$ orbitals with respect to the group backbone.

The N K-edge spectra of the films prepared by UVPER in Figure $4 \mathrm{~b}$ mimic the absorption structure of the C12N3/Au case, establishing, in agreement with the contact angle and XPS data, the formation of mixed $\mathrm{C} 12 / \mathrm{C} 12 \mathrm{~N} 3$ monolayers and intact character of the azide groups in these films. The intensity of the characteristic absorption features increases with increasing dose, in accordance with the contact angle and XPS data, establishing once more that the portion of $\mathrm{C} 12 \mathrm{~N} 3$ in the mixed $\mathrm{C} 12 / \mathrm{C} 12 \mathrm{~N} 3$ SAMs can be precisely controlled by UV dose. The $90^{\circ}-20^{\circ} \mathrm{N}$ K-edge spectra of these films exhibit pronounced linear dichroism, with the similar signs of the difference peaks as for $\mathrm{C} 12 \mathrm{~N} 3 / \mathrm{Au}$ (Figure $4 \mathrm{~d}$ ). This suggests, in agreement with the $\mathrm{C} \mathrm{K}$-edge data that (i) azide substitution does not result in disordering of the resulting AT monolayers and (ii) the molecular order is persistent upon the mixture of $\mathrm{C} 12$ and $\mathrm{C} 12 \mathrm{~N} 3$. Note that in the given case, the lower intensities of the difference peaks in the $90^{\circ}-20^{\circ}$ spectra of the $\mathrm{C} 12 / \mathrm{C} 12 \mathrm{~N} 3$ SAMs do not necessary suggest a lower extent of the orientational order in these systems as compared to $\mathrm{C} 12 / \mathrm{Au}$, since these intensities should be "normalized" to those in the $55^{\circ}$ spectra (Figure $4 \mathrm{~b}$ ). Quantitative evaluation of the N K-edge NEXAFS data within the standard procedure, ${ }^{31,36}$ relying on the intensity of the $\pi^{*}$ resonances, gives average tilt angles of the azide backbones of $28^{\circ}, 29^{\circ}$, and $30^{\circ}$ for $\mathrm{C} 12 \mathrm{~N} 3 / \mathrm{Au}$ and $\mathrm{C} 12 / \mathrm{C} 12 \mathrm{~N} 3 \mathrm{SAMs}$ prepared at 5 and $10 \mathrm{~J} / \mathrm{cm}^{2}$, respectively (with a standard accuracy of such an evaluation, $\pm 3^{\circ}$ ). So, it seems the azide groups are well-ordered and oriented upright, in agreement with the orientation of the alkyl backbones. Also, the values support the conclusion that the orientational order of the $\mathrm{C} 12 / \mathrm{C} 12 \mathrm{~N} 3 \mathrm{SAMs}$ is close to that of $\mathrm{C} 12 \mathrm{~N} 3 / \mathrm{Au}$, even though slightly lower. 
Note that the results of the numerical evaluation of the $\mathrm{N}$ 1s XPS and $\mathrm{N}$ K-edge NEXAFS spectra of the mixed $\mathrm{C} 12 / \mathrm{C} 12 \mathrm{~N} 3$ monolayers prepared by UVPER in terms of the signal intensity, taking the spectra of $\mathrm{C} 12 \mathrm{~N} 3 / \mathrm{Au}$ as the references, agree well with the results of the contact angle measurements (Figure 2). In particular, the portion of C12N3 in the C12/C12N3 films were estimated at $80 \%$ by XPS and $93 \%$ by the NEXAFS spectroscopy at a dose of 10 $\mathrm{J} / \mathrm{cm}^{2}$, which is in excellent agreement with the value of $91 \%$ determined on the basis of the contact angle data (Figure 2).

The next step of the experimental procedure for the $\mathrm{C} 12$ template was the click reaction with EFB (step 2 in Figure 2a). The results of this step were monitored by XPS. The N 1s (a) and F 1s (b) XPS spectra acquired after the click reaction are presented in Figures $5 \mathrm{a}$ and 5b, respectively, including the data for both $\mathrm{C} 12 / \mathrm{C} 12 \mathrm{~N} 3 \mathrm{SAMs}$ and reference $\mathrm{C} 12 \mathrm{~N} 3$ monolayers. The presence of the EFB-characteristic F 1s emission in the spectra of all samples (Figure 5b) establishes an efficient click reaction. Significantly, the character of the N 1s spectra changed completely as compared to the situation before the click reaction: instead of two emissions at BEs of 400.7 and $404.1 \mathrm{eV}$ (Figure 3), there is only one emission at a BE of $400.1 \mathrm{eV}$ (Figure 5a). Consequently, the yield of the click reaction should be close to $100 \%$. According to this assumption, the dependence of the $\mathrm{N}$ 1s and $\mathrm{F}$ 1s intensities on UV dose after the click reaction in Figure $5 \mathrm{c}$ mimics the curve for the portion of $\mathrm{C} 12 \mathrm{~N} 3$ before the click reaction in Figure 2. The data in Figure 5c are an additional evidence that the mixed C12/C12N3 SAMs can be prepared successfully by UVPER, in a broad range of compositions precisely controlled by UV dose, along with the finding that these mixed SAMs are highly efficient with respect to the click reaction, similar to the one-component $\mathrm{C} 12 \mathrm{~N} 3$ monolayer.

\subsection{EGn/C12N3 Monolayers}

The results of UVPER for the EGn templates (step 1 in Figure 1b) were monitored by contact angle goniometry, XPS, and NEXAFS spectroscopy. In the case of the goniometry, the portion of $\mathrm{C} 12 \mathrm{~N} 3$ in the EG3/C12N3 SAMs was evaluated on the basis of the Cassie law, in the same way as for the $\mathrm{C} 12 / \mathrm{C} 12 \mathrm{~N} 3$ films, with the contact angles of the single-component films taking as references. In the case of XPS, the intensity of the N 1s signal characteristic of the azide group was evaluated, again - in the same way as for the $\mathrm{C} 12 / \mathrm{C} 12 \mathrm{~N} 3$ films, with the intensity 
of the $\mathrm{N} 1 \mathrm{~s}$ signal for $\mathrm{C} 12 \mathrm{~N} 3 / \mathrm{Au}$ taking as reference. The results of the above evaluation are presented in Figure 6, with the goniometry- and XPS-derived values being in good agreement with each other (Figures $6 \mathrm{a}$ and $6 \mathrm{~b}$, respectively). According to these results, the portion of $\mathrm{C} 12 \mathrm{~N} 3$ in the mixed EG3/C12N3 films prepared by UVPER can be varied from $\sim 10 \%$ to $60-70 \%$ upon UV dose variation from 0 to $411 \mathrm{~J} / \mathrm{cm}^{2}$. In the EG6/C12N3 case, the portion of $\mathrm{C} 12 \mathrm{~N} 3$ can be varied within a shorter range, from $\sim 5 \%$ to $42-44 \% \%$, which is understandable considering that the efficiency of promoted exchange reaction decreases with increasing molecular length of the primary template. ${ }^{5,7}$ The higher doses required for the efficient exchange as compared to the $\mathrm{C} 12 / \mathrm{C} 12 \mathrm{~N} 3$ case (Figure 2) are solely explained by the lower efficiency of UV light at a longer wavelength (see Section 1). ${ }^{7,23}$

The portions of DBPB after the respective catalyst-free click reaction (step 2 in Figure 1b) for the EG3/C12N3 and EG6/C12N3 SAMs are given in Figure 7 as functions of UV dose within UVPER. These portions, determined on the basis of the $\mathrm{N}$ 1s data, could be varied from $\sim 10$ to $50-60 \%$, depending on the UV dose. The portions of specifically (avidin) and non-specifically (BSA) attached proteins after the exposure of the DBPB-functionalized $\mathrm{EG} 3 / \mathrm{C} 12 \mathrm{~N} 3$ and $\mathrm{EG} 3 / \mathrm{C} 12 \mathrm{~N} 3 \mathrm{SAMs}$ to the respective protein solutions (step 3 in Figure 1b) are presented in Figure 8 as functions of UV dose. The values were derived from the $\mathrm{N} 1 \mathrm{~s}$ XPS spectra and normalized to those for the DBPB-functionalized single-component $\mathrm{C} 12 \mathrm{~N} 3$ monolayer undergone the same procedure. As seen in this figure, the attachment of avidin, relying on the presence of the specific biotin receptors, is always superior as compared to that of the non-specific protein (BSA). The coverage of avidin could be controlled by the density of the specific receptors, determined in their turn, by the UV dose applied within the UVPER procedure. The lower avidin coverage in the case of the EG6/C12N3 templates is well explained by the lower density of the $\mathrm{C} 12 \mathrm{~N} 3$ moieties (Figure 6) and, subsequently, biotin docking sites (Figure 7) in the given case as compared to the EG3/C12N3 system. The non-specific adsorption could be regretfully not completely avoided, which is presumably related to the non-complete exchange of the UV-damaged molecules. Consequently, the procedure can be further optimized.

The entire experimental procedure in the case of the EGn templates was also monitored by the NEXAFS spectroscopy. The respective data are presented in Figure 9, for the EG6 case. 
These data include $55^{\circ} \mathrm{N}$ K-edge NEXAFS spectra of the pristine EG6 and C12N3 SAMs, EG6 monolayers after the non-promoted $\left(0 \mathrm{~J} / \mathrm{cm}^{2}\right)$ and promoted $\left(411 \mathrm{~J} / \mathrm{cm}^{2}\right.$ as a representative dose) exchange reaction with $\mathrm{C} 12 \mathrm{~N} 3$ (step 1 in Figure 1b), the resulting EG6/C12N3 films after the catalyst-free click reaction with DBPB (step 2 in Figure 1b) and after the subsequent exposure to BSA and avidine (step 3 in Figure 1b). As expected, no absorption structure at the $\mathrm{N} \mathrm{K-edge} \mathrm{was} \mathrm{observed} \mathrm{for} \mathrm{the} \mathrm{nitrogen-free} \mathrm{EG6} \mathrm{template,}$ whereas the $\mathrm{C} 12 \mathrm{~N} 3$ reference exhibited a clear signature of the azide groups (see discussion related to Figure $4 b$ ). Tiny features at the positions of the respective resonances could be found in the spectrum of EG6 monolayers after the non-promoted $\left(0 \mathrm{~J} / \mathrm{cm}^{2}\right)$ exchange reaction, in agreement with the data in Figure 6. The characteristic signal of the azide group is, however, well perceptible in the case of UVPER $\left(411 \mathrm{~J} / \mathrm{cm}^{2}\right)$, being also quantitatively well in agreement with the analogous values derived from the contact angle and XPS data (Figure 6). The click reaction with DBPB results in significant modification of the NEXAFS spectra, as can be expected. Further, the exposure of the DBPB functionalized EG3/EG6 films to BSA (non-specific) results in only a slight enhancement of the absorption structure, in accordance with low extent of non-specific adsorption (Figure 8). In contrast, the exposure of the same template to avidine results in much stronger signal, corresponding to the specific attachment of this protein to the biotine binding sites. Note that the NEXAFS spectra of proteins are only weakly sensitive to their composition because of the superposition of the contributions from individual amino acids. ${ }^{40}$

The UVPER-based experimental procedures, illustrated in Figure 1, can also be applied in the lithographic fashion, relying e.g. on proximity printing lithography ${ }^{7,8,23}$ or existing experimental setup employing scanning near field optical microscope ${ }^{26,27}$ or interferometric technique $^{28}$. Note, however, that the last two setups are custom-designed and employ UV light with quite a short wavelength $(254 \mathrm{~nm})$. In contrast, as an example, we performed UVPER lithography with the entirely commercial setup described in Section 2 and, in detail, in ref 24. The key element of this setup is a computer-controlled digital micromirror device (DMD) chip combined with a suitable optics and a powerful light-emitting diode (LED) UV source. ${ }^{24}$ Representative SEM images of specific protein patterns prepared on the DBPB-functionalized EG3/C12N3 and EG6/C12N3 templates, fabricated by a combination of UVPER-based 
lithography and subsequent catalyst-free click reaction with DBPB, are shown in Figure 10. The patterns represent an array of circular spots generated in the computer by a standard graphical software (see Section 2). The protein coverage was varied between the successive spot rows in a gradient, step-like fashion by selection of a proper UV dose within the UVPER procedure (step 1 in Figure 1b). Four different doses were applied, resulting in distinct protein adsorption contrast between four successive spot rows. Note that the patterning is possible not only under ambient conditions (given case) but also in aqueous environment. ${ }^{25}$

\section{Conclusions}

In the given study, we demonstrated the possibility of UV light promoted exchange reaction (UVPER) between the primary AT SAM templates and an azide-bearing substituent (C12N3), capable of click reaction with ethynyl-bearing species. This reaction resulted in the mixed AT/C12N3 monolayers. As primary matrix we used either non-substituted (C12) or OEG-substituted (EG3 and EG6) AT SAMs, targeting mixed SAMs of chemical and biological significance. To demonstrate the flexibility of the approach we used UV light with two different wavelengths, viz. $254 \mathrm{~nm}$ and $375 \mathrm{~nm}$, applying it to the non-substituted and OEG-substituted AT SAMs, respectively. Individual steps of the experimental procedure were monitored by contact angle goniometry, XPS, and NEXAFS spectroscopy.

In all cases, we were able to vary the portion of the $\mathrm{C} 12 \mathrm{~N} 3$ moieties in the mixed $\mathrm{C} 12 / \mathrm{C} 12 \mathrm{~N} 3$ and C12/EGn monolayers in controlled fashion by selection of a suitable UV dose within the UVPER procedure. This portion could be varied from $10-20 \%$ to $90 \%$ in the case of the $\mathrm{C} 12$ template and from $0-10 \%$ to $40-70 \%$ in the case of the EG3 and EG6 templates. The surface density of the chemically active azide groups embedded in the non-reactive primary matrix could be varied accordingly, as demonstrated by the subsequent click reaction between the $\mathrm{C} 12 / \mathrm{C} 12 \mathrm{~N} 3$ templates and EFB as well as by the catalyst-mediated and catalyst-free click reactions between the $\mathrm{EGn} / \mathrm{C} 12 \mathrm{~N} 3$ templates and $\mathrm{BPA}$ and $\mathrm{DBPB}$, respectively. The latter reactions resulted in the preparation of templates for specific protein adsorption, comprising of biotin-bearing moieties embedded in the protein-repelling EGn matrix. The density of the biotin receptors was varied according to the density of the $\mathrm{C} 12 \mathrm{~N} 3$ moieties in the EGn/C12N3 films, i.e. directly controlled by the UV dose within the UVPER procedure. The templates 
exhibited much higher affinity to the specific protein (avidin) as compared to non-specific one (BSA). The surface density of the specifically bound proteins could be varied in accordance with the density of the biotin receptors, i.e. directly controlled by the UV dose within the UVPER procedure. The entire approach was extended to lithography, relying on a commercial, maskless UV lithography setup. Representative gradient patterns of specifically attached avidin in the protein-repelling EGn matrix were fabricated.

The procedures described in this study are not limited to the representative moieties (EFB, $\mathrm{DBPB}$, and BPA) used for the click reaction in the given case but generally applicable to a broad variety of functional molecules bearing a suitable group for the click reaction with azide. Also, the combination of these procedures with lithography can be performed in different fashions, relying on particular lithographic setups. Significantly, the fabrication of both mixed SAMs and the related lithographic patterns can be performed in a broad range of wavelengths, as demonstrated by utilizing UV light with wavelengths of 254 and $375 \mathrm{~nm}$.

\author{
Associatted content \\ Supporting Information \\ The Supporting Information is available free of charge on the ACS Publication website at \\ DOI: \\ Description of the synthesis procedure for $\mathrm{C} 12 \mathrm{~N} 3$ along with the respective ${ }^{1} \mathrm{H}-,{ }^{13} \mathrm{C}-\mathrm{NMR}$ \\ and MS spectra (PDF).
}

\title{
Author Information
}

\section{Corresponding Author}

*E-mail: michael.zharnikov@urz.uni-heidelberg.de.

\section{Notes}

The authors declare no competing financial interest. 


\section{Acknowledgments}

We thank Andreas Terfort for the joint purchasing of the DLP setup, Helmholtz Zentrum Berlin for the allocation of synchrotron radiation beamtime at Bessy II, and A. Nefedov and Ch. Wöll for the technical cooperation during the experiments at BESSY II. M.Z. appreciates financial support of the German Research Foundation (DFG). Y.R. thanks the China Scholarship Council (CSC) for financial support. 


\section{Figure captions}

Schema 1. SAM precursors and substituent of this study, along with the respective abbreviations.

Schema 2. Compounds for the click reaction with the azide group, along with the respective abbreviations.

Figure 1. Schematic of the experimental procedure. The procedure includes the exposure of the primary C12 (a) and EGn (b) SAMs to UV light with a wavelength of either $254 \mathrm{~nm}$ (C12) or $375 \mathrm{~nm}(\mathrm{EGn})$, promoted exchange reaction with $\mathrm{C} 12 \mathrm{~N} 3$, catalyst-mediated click reaction with $\mathrm{EFB}(\mathrm{C} 12 / \mathrm{C} 12 \mathrm{~N} 3)$ and BPA $(\mathrm{EGn} / \mathrm{C} 12 \mathrm{~N} 3)$ as well as catalyst-free click reaction with DBPB (EGn/C12N3), and test for non-specific and specific protein adhesion (for EGn/C12N3 only). The individual steps are numbered. They were monitored by several complementary experimental techniques, as described in the text.

Figure 2. Advancing water contact angle (black squares and solid line) and portion of C12N3 (blue circles and solid line) for the C12/C12N3 SAMs fabricated by UVPER (step 1 in Figure 1a). The UV dose was varied. The portions of $\mathrm{C} 12 \mathrm{~N} 3$ are given with respect to the single-component $\mathrm{C} 12 \mathrm{~N} 3$ monolayer taken as a reference.

Figure 3. $\mathrm{N} 1 \mathrm{~s}$ XPS spectra of the $\mathrm{C} 12 \mathrm{SAMs}$ after non-promoted $\left(0 \mathrm{~J} / \mathrm{cm}^{2}\right)$ and promoted (variable dose) exchange reaction with $\mathrm{C} 12 \mathrm{~N} 3$ (step 1 in Figure 1a), along with the spectrum of the single-component $\mathrm{C} 12 \mathrm{~N} 3$ monolayer taken as a reference (bottom curve). The doses are marked at the spectra.

Figure 4. $\mathrm{C}(\mathrm{a}, \mathrm{c})$ and $\mathrm{N}(\mathrm{b}, \mathrm{d}) \mathrm{K}$-edge NEXAFS spectra of the C12 SAMs after promoted (variable dose) exchange reaction with $\mathrm{C} 12 \mathrm{~N} 3$ (step 1 in Figure 1a), along with the spectra of the single-component $\mathrm{C} 12 \mathrm{~N} 3$ and $\mathrm{C} 12$ monolayers taken as references (bottom curves). The doses are marked at the spectra. Two kinds of spectra are presented, viz. the spectra acquired at an X-ray incidence angle of $55^{\circ}(\mathrm{a}, \mathrm{b})$, and the difference between the spectra collected under the normal $\left(90^{\circ}\right)$ and grazing $\left(20^{\circ}\right)$ incidence geometry $(\mathrm{c}, \mathrm{d})$. Individual absorption resonances are marked by numbers (see text for the assignments). 
Figure 5. $\mathrm{N} 1 \mathrm{~s}$ (a) and $\mathrm{F} 1 \mathrm{~s}$ (b) XPS spectra of the mixed C12/C12N3 SAMs and the single-component C12N3 monolayer (reference) after the click reaction with EFB (step 2 in Figure 1a). The mixed SAMs were prepared by UVPER (variable dose as marked at the spectra). (c) Portion of EFB derived from the $\mathrm{N}$ 1s data (blue circles and solid line) and F 1s data (red squares and solid line) as function of UV dose. The values were normalized to that for the single-component $\mathrm{C} 12 \mathrm{~N} 3$ monolayer.

Figure 6. Portions of $\mathrm{C} 12 \mathrm{~N} 3$ in the $\mathrm{EG} 3 / \mathrm{C} 12 \mathrm{~N} 3$ (black squares and solid line) and EG6/C12N3 (red circles and solid line) SAMs fabricated by UVPER (step 1 in Figure 1b) as functions of UV dose. The values were calculated on the basis of advancing water contact angle (a) and intensity of the characteristic $\mathrm{N} \mathrm{1s}$ emissions (b). The portions of C12N3 are given with respect to the single-component $\mathrm{C} 12 \mathrm{~N} 3$ monolayer taken as a reference.

Figure 7. Portions of DBPB after the respective catalyst-free click reaction (step 2 in Figure 1b) for the EG3/C12N3 (black squares and solid line) and EG6/C12N3 (red circles and solid line) SAMs as functions of UV dose within UVPER. The values were normalized to those for the single-component $\mathrm{C} 12 \mathrm{~N} 3$ monolayer undergone the same procedure.

Figure 8. Portion of avidin after the exposure of the DBPB-functionalized EG3/C12N3 (black filled squares and solid line) and EG6/C12N3 (red filled circles and solid line) SAMs to a solution of this protein (step 3 in Figure 1b) as functions of UV dose. Portion of BSA after the exposure of the DBPB-functionalized EG3/C12N3 (gray open squares and solid line) and EG6/C12N3 (rose open circles and solid line) SAMs to a solution of this protein (step 3 in Figure 1b) as functions of UV dose. The portions were derived from the N 1s XPS spectra. The values were normalized to those for the DBPB-functionalized, single-component C12N3 monolayer undergone the same procedure.

Figure 9. $55^{\circ} \mathrm{N}$ K-edge NEXAFS spectra of the pristine EG6 and C12N3 SAMs, EG6 monolayers after the non-promoted $\left(0 \mathrm{~J} / \mathrm{cm}^{2}\right)$ and promoted $\left(411 \mathrm{~J} / \mathrm{cm}^{2}\right)$ exchange reaction with $\mathrm{C} 12 \mathrm{~N} 3$ (step 1 in Figure 1b), the resulting EG6/C12N3 films after the catalyst-free click reaction with DBPB (step 2 in Figure 1b), and after the subsequent exposure of the DBPB functionalized EG3/C12N3 films to BSA and avidine (step 3 in Figure 1b). 
Figure 10. SEM images of specific protein patterns prepared on the DBPB-functionalized EG6/C12N3 (a) and EG3/C12N3 (b) templates fabricated by a combination of UVPER-based lithography and subsequent catalyst-free click reaction with DBPB. The patterns represent an array of circular spots. The protein coverage was varied between the spot rows in a gradient fashion by selection of a proper UV dose within the UVPER procedure. The protein coverage variation can be traced directly in the images by the different contrast of the spots. The doses for the four successive rows (from top to bottom) were $685,411,137$, and $68 \mathrm{~J} / \mathrm{cm}^{2}$; the respective coverages can be derived from Figure 9, with the value for $685 \mathrm{~J} / \mathrm{cm}^{2}$ being extrapolated. The scale bars in all images are $200 \mu \mathrm{m}$. Black spots in the middle of the patterns are imaging artifacts (SEM aberrations because of a large field of view). 


\section{References}

(1) Ulman, A. Formation and Structure of Self-Assembled Monolayers. Chem. Rev. 1996, 96, 1533-1554.

(2) Schreiber, F. Self-Assembled Monolayers: From 'Simple' Model Systems to Biofunctionalized Interfaces. J. Phys.: Condens. Matter 2004, 16, R881-R900.

(3) Love, J. C.; Estroff, L. A.; Kriebel, J. K.; Nuzzo, R. G.; Whitesides, G. M. Self-Assembled Monolayers of Thiolates on Metals as a Form of Nanotechnology. Chem. Rev. 2005, 105, 1103-1169.

(4) Ballav, N.; Shaporenko, A.; Terfort, A.; Zharnikov, M. A Flexible Approach to the Fabrication of Chemical Gradients. Adv. Mater. 2007, 19, 998-1000.

(5) Ballav, N.; Shaporenko, A.; Krakert, S.; Terfort, A.; Zharnikov, M. Tuning the Exchange Reaction Between a Self-Assembled Monolayer and Potential Substituents by Electron Irradiation. J. Phys. Chem. C 2007, 111, 7772-7782.

(6) Ballav, N.; Weidner, T.; Zharnikov, M. UV-Promoted Exchange Reaction as a Tool for Gradual Tuning the Composition of Binary Self-Assembled Monolayers and Chemical Lithography. J. Phys. Chem. C 2007, 111, 12002-12010.

(7) Jeyachandran, Y. L.; Terfort, A.; Zharnikov, M. Controlled Modification of Protein-Repelling Self-Assembled Monolayers by Ultraviolet Light: The Effect of the Wavelength. J. Phys. Chem. C 2012, 116, 9019-9028.

(8) Jeyachandran, Y. L.; Zharnikov, M. A Comprehensive Analysis of the Efect of Electron Irradiation on Oligo(ethylene glycol) Terminated Self-Assembled Monolayers Applicable for Specific and Non-specific Patterning of Proteins. J. Phys. Chem. C 2012, 116, 14950-14959.

(9) Ballav, N.; Schilp, S.; Zharnikov, M. Electron Beam Chemical Lithography with Aliphatic Self-Assembled Monolayers. Angew. Chem. Int. Ed. 2008, 47, 1421-1424.

(10) Khan, M. N.; Tjong, V.; Chilkoti, A.; Zharnikov, M. Fabrication of ssDNA/Oligo(ethylene glycol) Monolayers and Complex Nanostructures by an Irradiation-Promoted Exchange Reaction. Angew. Chem. Int. Ed. 2012, 51, 10303-10306.

(11) Rostovtsev, V. V.; Green, L. G.; Fokin, V. V.; Sharpless, K. B. A Stepwise Huisgen Cycloaddition Process: Copper(I)-Catalyzed Regioselective "Ligation" of Azides and Terminal Alkynes. Angew. Chem. Int. Ed. 2002, 41, 2596-2599. 
(12) Collmann, J. P.; Devaraj, N. K.; Eberspacher, T. P. A.; Chidsey, C. E. D. Mixed Azide-Terminated Monolayers: A Platform for Modifying Electrode Surfaces. Langmuir 2006, $22,2457-2464$.

(13) Lutz, J.-F. 1,3-dipolar Cycloadditions of Azides and Alkynes: A Universal Ligation Tool in Polymer and Materials Science. Angew. Chem. Int. Ed. 2007, 46, 1018-1025.

(14) Chelmowski, R.; Käfer, D.; Köster, S. D.; Klasen, T.; Winkler, T.; Terfort, A.; Metzler-Nolte, N.; Wöll, C. Postformation Modification of SAMs: Using Click Chemistry to Functionalize Organic Surfaces. Langmuir 2009, 25, 11480-11485.

(15) Kappe, C. O.; Van der Eycken E. Click Chemistry Under Non-Classical Reaction Conditions. Chem. Soc. Rev. 2010, 39, 1280-1290.

(16) Gallardo, I. F.; Webb, L. J. Tethering Hydrophobic Peptides to Functionalized Self-Assembled Monolayers on Gold through Two Chemical Linkers Using the Huisgen Cycloaddition, Langmuir 2010, 26, 18959-18966.

(17) Grosdemange, C. P.; Simon, E. S.; Prime, K. L.; Whitesides, G. M. Formation of Self-Assembled Monolayers by Chemisorption of Derivatives of Oligo(ethylene glycol) of Structure $\mathrm{HS}\left(\mathrm{CH}_{2}\right)_{11}\left(\mathrm{OCH}_{2} \mathrm{CH}_{2}\right)_{\mathrm{m}} \mathrm{OH}$ on Gold. J. Am. Chem. Soc. 1991, 113, 12-20.

(18) Prime, K. L.; Whitesides, G. M. Adsorption of Proteins onto Surfaces Containing End-Attached Oligo(ethylene oxide): A Model System Using Self-Assembled Monolayers. $J$. Am. Chem. Soc. 1993, 115, 10714-10721.

(19) Harder, P.; Grunze, M.; Dahint, R.; Whitesides, G. M.; Laibinis, P. E. Molecular Conformation in Oligo(ethylene glycol)-Terminated Self-Assembled Monolayers on Gold and Silver Surfaces Determines Their Ability To Resist Protein Adsorption J. Phys. Chem. B 1998, $102,426-436$.

(20) Benesch, J.; Svedhem, S.; Svensson, S. C. T.; Valiokas, R.; Liedberg, B.; Tengvall, P. Protein Adsorption to Oligo(ethylene glycol) Self-Assembled Monolayers: Experiments with Fibrinogen, Heparinized Plasma, and Serum. J. Biomater. Sci. Polym. Ed. 2001, 12, 581-597.

(21) Herrwerth, S.; Eck, W.; Reinhardt, S.; Grunze, M. Factors that Determine the Protein Resistance of Oligoether Self-Assembled Monolayers - Internal Hydrophilicity, Terminal Hydrophilicity, and Lateral Packing Density. J. Am. Chem. Soc. 2003, 125, 9359-9366.

(22) Rosenhahn, A.; Schilp, S.; Kreuzer, J.; Grunze, M. The Role of "Inert" Surface 
Chemistry in Marine Biofouling Prevention. Phys. Chem. Chem. Phys. 2010, 12, 4275-4286.

(23) Jeyachandran, Y. L.; Weber, T.; Terfort, A.; Zharnikov, M. Application of Long Wavelength Ultraviolet Radiation for Modification and Patterning of Protein-Repelling Monolayers. J. Phys. Chem. C 2013, 117, 5824-5830.

(24) Jeyachandran, Y. L.; Meyerbröker, N.; Terfort, A.; Zharnikov, M. Maskless Ultraviolet Projection Lithography with a Biorepelling Monomolecular Resist, J. Phys. Chem. C 2015, 119, 494-501.

(25) Weber, T.; Meyerbröker, N.; Khan Hira, N.; Zharnikov, M.; Terfort, A. UV-mediated Tuning of Surface Biorepulsivity in Aqueous Environment. Chem. Comm. 2014, 50, $4325-4327$.

(26) Montague, M.; Ducker, R. E.; Chong, K. S. L.; Manning, R. J.; Rutten, F. J. M.; Davies, M. C.; Leggett, G. J. Fabrication of Biomolecular Nanostructures by Scanning Near-Field Photolithography of Oligo(ethylene glycol)-Terminated Self-Assembled Monolayers. Langmuir 2007, 23, 7328-7337.

(27) Ducker, R. E.; Janusz, S.; Sun, S.; Leggett, G. J. One-Step Photochemical Introduction of Nanopatterned Protein-Binding Functionalities to Oligo(ethylene glycol)-Terminated Self-Assembled Monolayers. J. Am. Chem. Soc. 2007, 129, 14842-14843.

(28) Adams, J.; Tizazu, G.; Janusz, S.; Brueck, S. R. J.; Lopez, G. P.; Leggett, G. J. Large-Area Nanopatterning of Self-Assembled Monolayers of Alkanethiolates by Interferometric Lithography. Langmuir 2010, 26, 13600-13606.

(29) Moulder, J. F.; Stickle, W. E.; Sobol, P. E.; Bomben, K. D. Handbook of X-ray Photoelectron Spectroscopy; Chastian, J., Ed.; Perkin-Elmer Corp.: Eden Prairie, MN, 1992.

(30) Nefedov, A. Wöll, C. Advanced Applications of NEXAFS Spectroscopy for Functionalized Surfaces, in Surface Science Techniques; Bracco, G.; Holst, B., Eds.; Springer Series in Surface Science 2013, 51, 277-306; Springer-Verlag, Berlin, Heidelberg, New York, Tokyo.

(31) Stöhr, J. NEXAFS spectroscopy; Springer-Verlag: Berlin, 1992.

(32) Batson, P. E. Carbon-1s Near-Edge-Absorption Fine-Structure in Graphite. Phys. Rev. $B$ 1993, 48, 2608-2610. 
(33) Wollman, E. W.; Kang, D.; Frisbie, C. D.; Lorkovic, I. M.; Wrighton, M. S. Photosensitive Self-Assembled Monolayers on Gold: Photochemistry of Surface-Confined Aryl Azide and Cyclopentadienylmanganese Tricarbonyl. J. Am. Chem. Soc. 1994, 116, $4395-4404$.

(34) Darlatt, E.; Traulsen, C. H.-H.; Poppenberg, J.; Richter, S.; Kühn, J.; Schalley, C. A.; Unger, W. E .S. Evidence of Click and Coordination Reactions on a Self-Assembled Monolayer by Synchrotron Radiation Based XPS and NEXAFS. J. Electron Spectr. Relat. Phenom. 2012, 185, 85-89.

(35) Bagus, P. S.; Weiss, K.; Schertel, A.; Wöll, Ch.; Braun, W.; Hellwig, H.; Jung, C. Identefication of Transitions into Rydberg States in the X-ray Absorption Spectra of Condensed Long-Chain Alkanes. Chem. Phys. Lett. 1996, 248, 129.

(36) Frey, S.; Shaporenko, A.; Zharnikov, M.; Harder, P.; Allara, D. L. Self-Assembled Monolayers of Nitrile-Functionalized Alkanethiols on Gold and Silver Substrates. J. Phys. Chem. B 2003, 107, 7716-7725.

(37) Schreiber, F. Structure and Growth of Self-Assembling Monolayers. Prog. Surf. Sci. 2000, 65, 151-256.

(38) Zharnikov, M.; Grunze, M. Spectroscopic Characterization of Thiol-Derived Self-Assembling Monolayers. J. Phys. Condens. Matter. 2001, 13, 11333-11365.

(39) Darlatt, E.; Nefedov, A.; Traulsen, C. H.-H.; Poppenberg, J.; Richter, S.; Dietrich, P. M.; Lippitz, A.; Illgen, R.; Kühn, J.; Schalley, C. A.; et al. Interpretation of Experimental N K NEXAFS of Azide, 1,2,3-Triazole and Terpyridyl Groups by DFT Spectrum Simulations. $J$. Electron Spectr. Relat. Phenom. 2012, 185, 621-624.

(40) Zubavichus, Y.; Shaporenko, A.; Grunze, M.; Zharnikov, M. Is X-ray Absorption Spectroscopy Sensitive to the Amino Acid Composition of Functional Proteins? J. Phys. Chem. B 2008, 112, 4478-4480. 


1
2
3
4
5
6
7
8
9
10
11
12
13
14
15
16
17
18
19
20
21
22
23
24
25
26
27
28
29
30
31
32
33
34
35
36
37
38
39
40
41
42
43
44
45
46
47
48
49
50
51
52
53
54
55
56
57
50

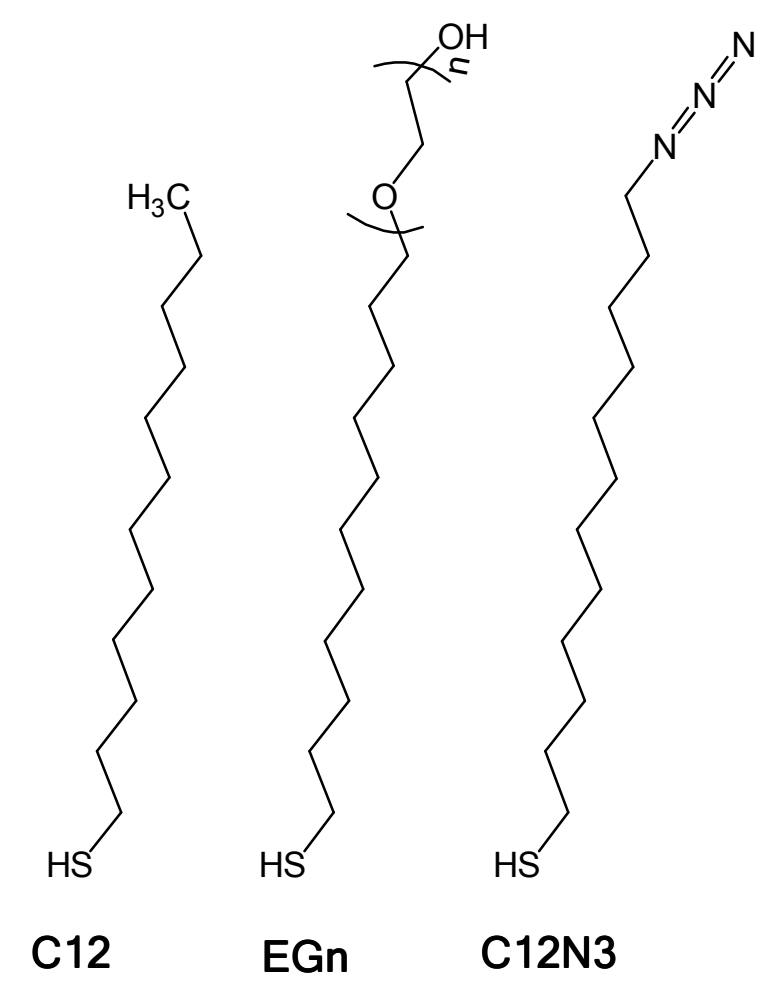

Schema 1 

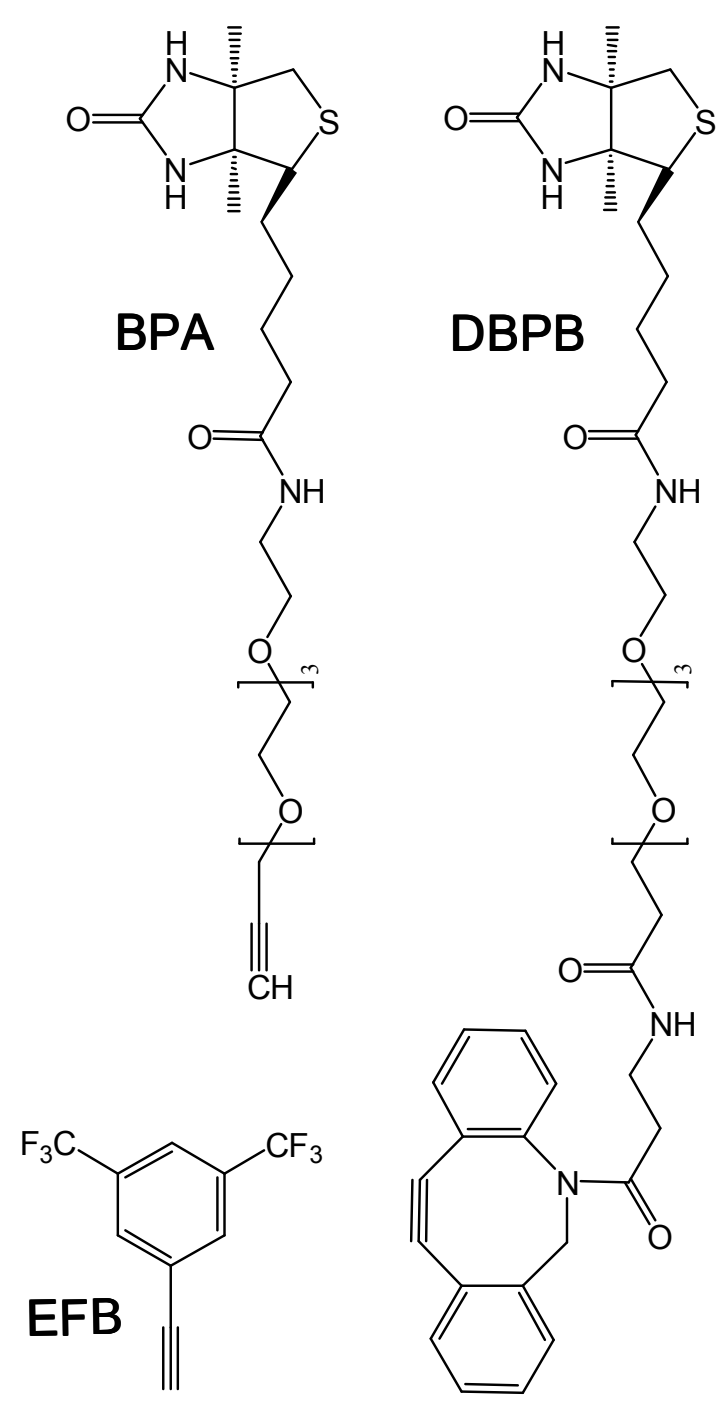

Schema 2 


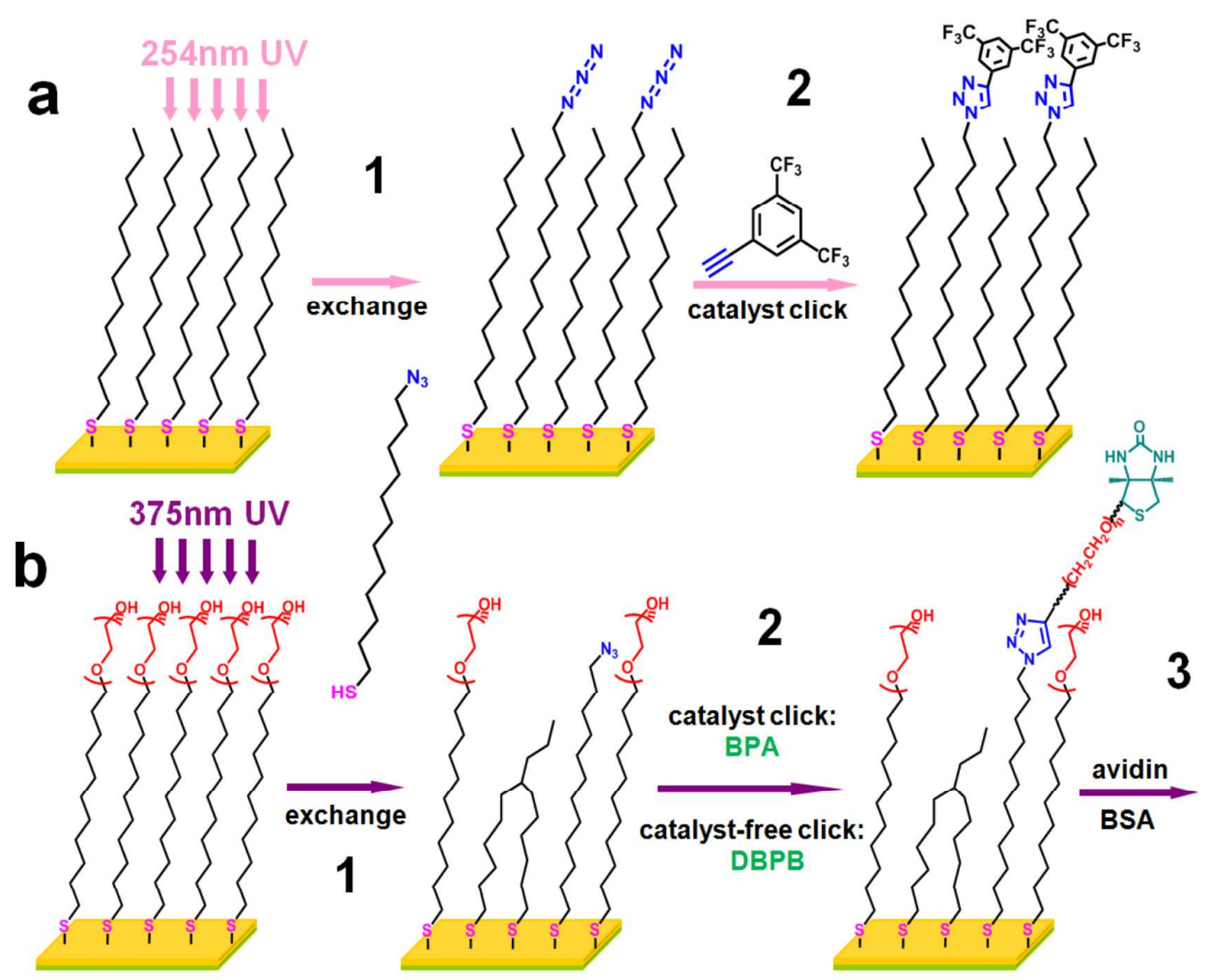

Figure 1 


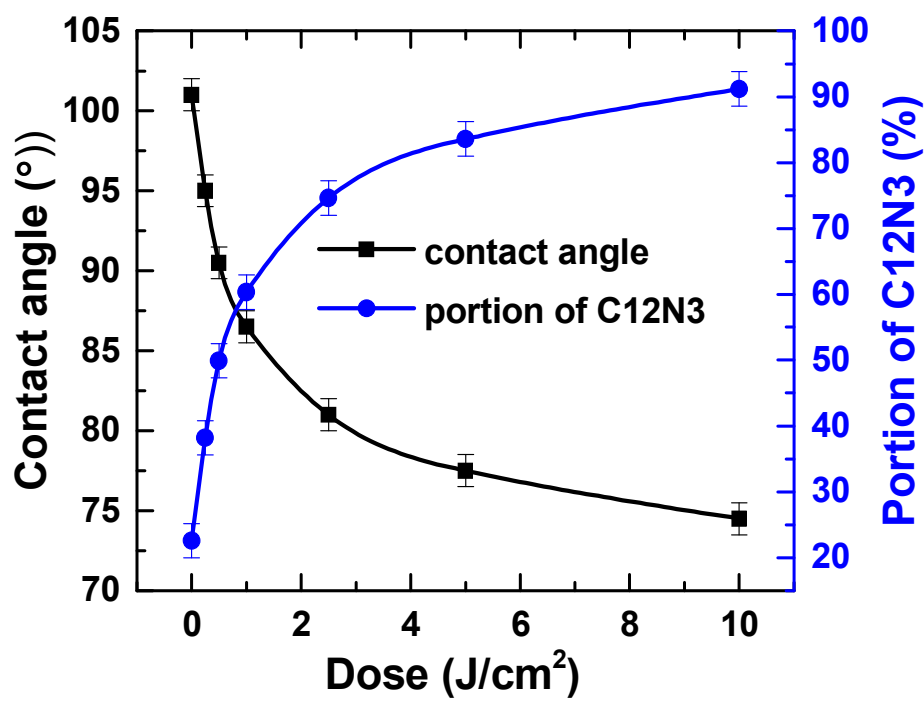

Figure 2

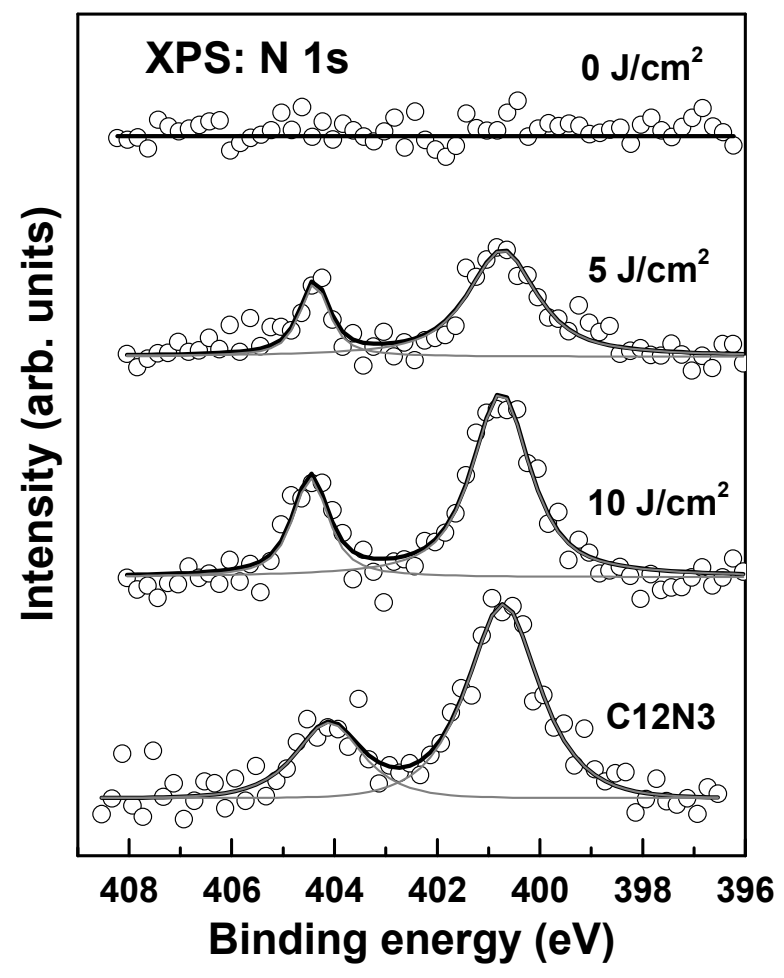

ACS Paragon Plus Environment 
Figure 3

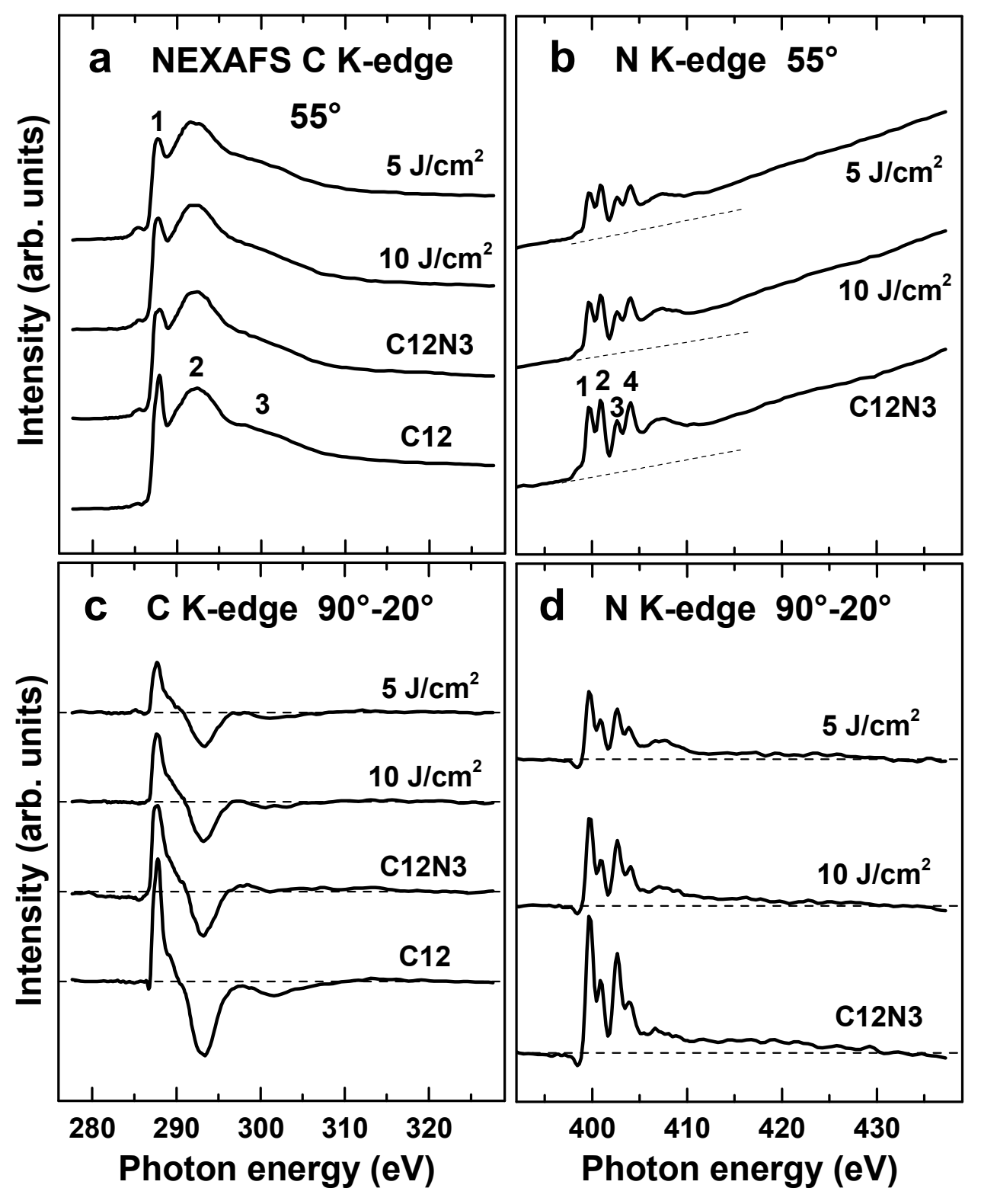

Figure 4 

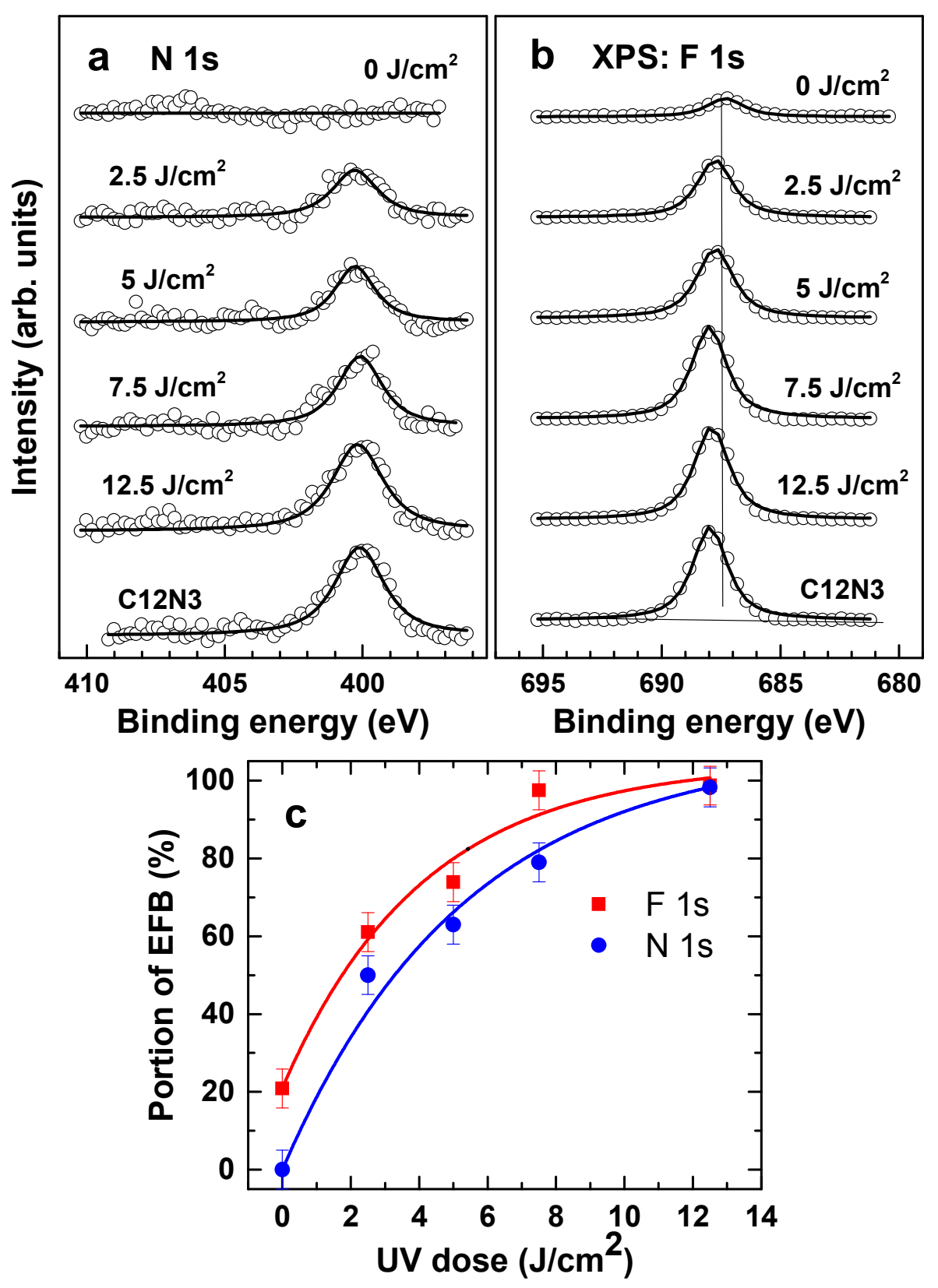

Figure 5 


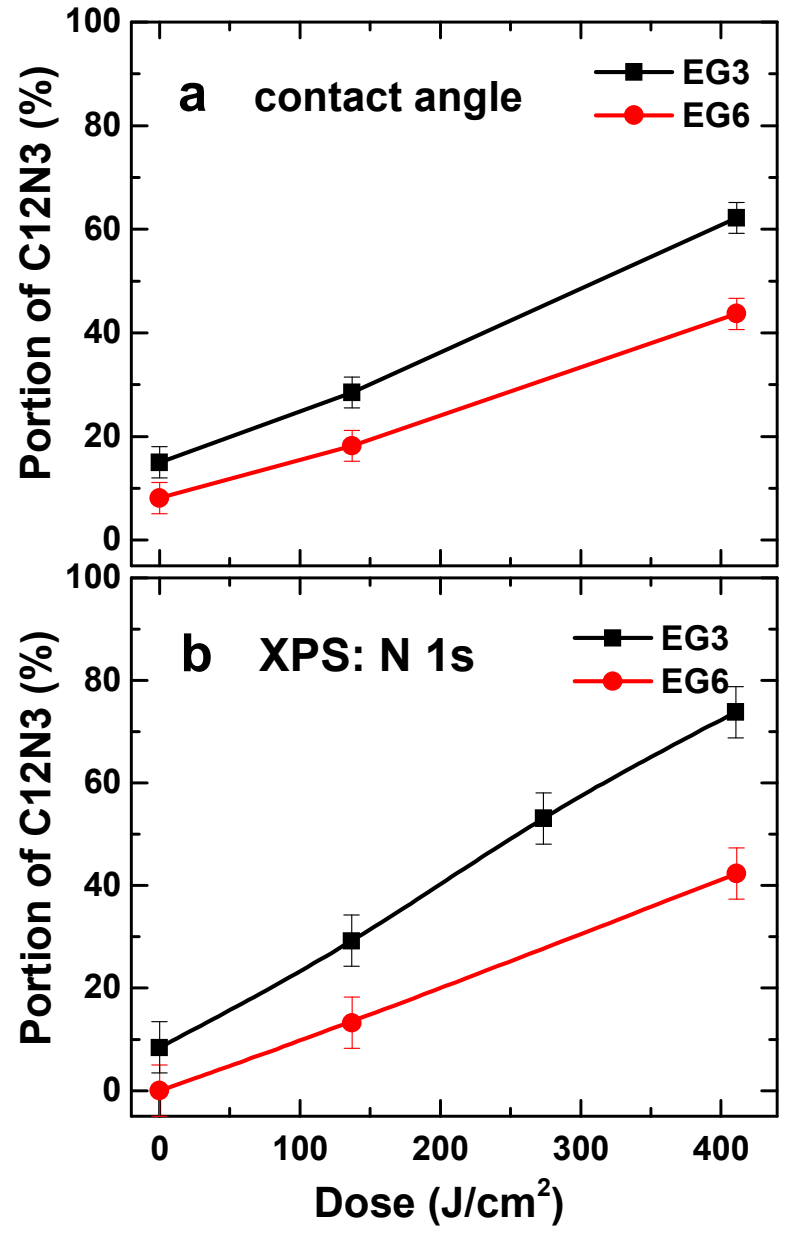

Figure 6 


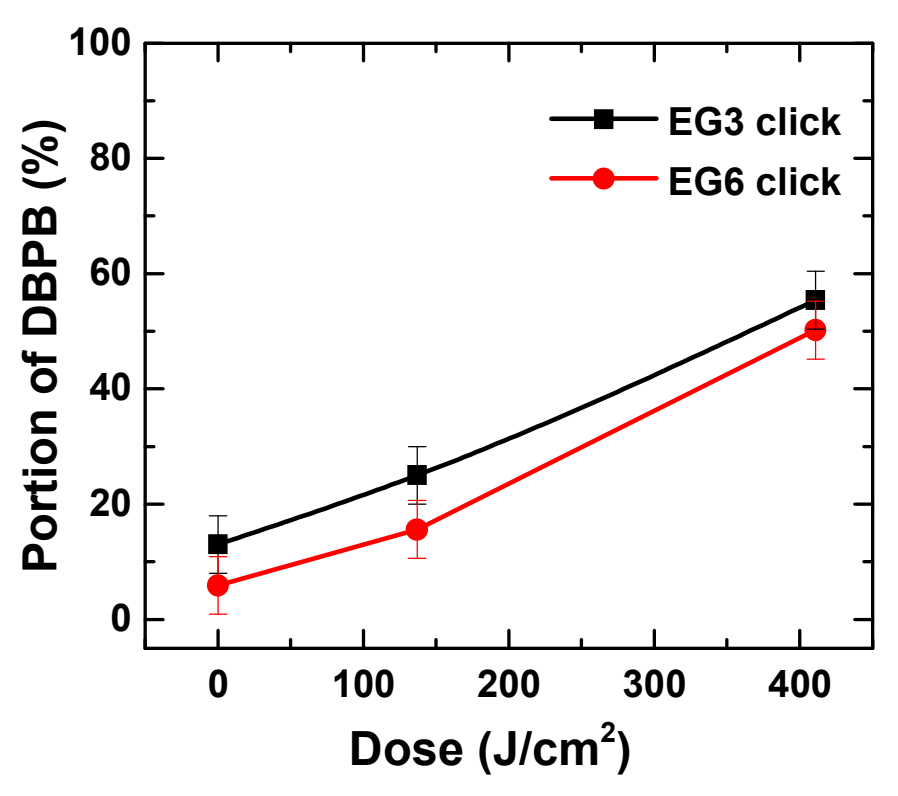

Figure 7

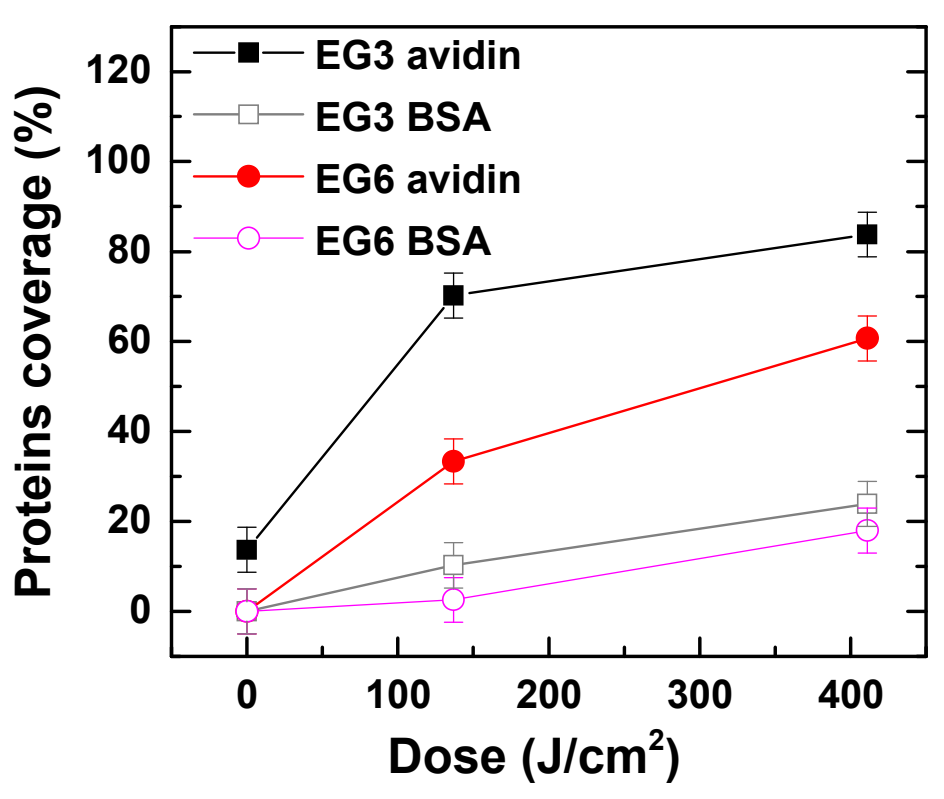

Figure 8 


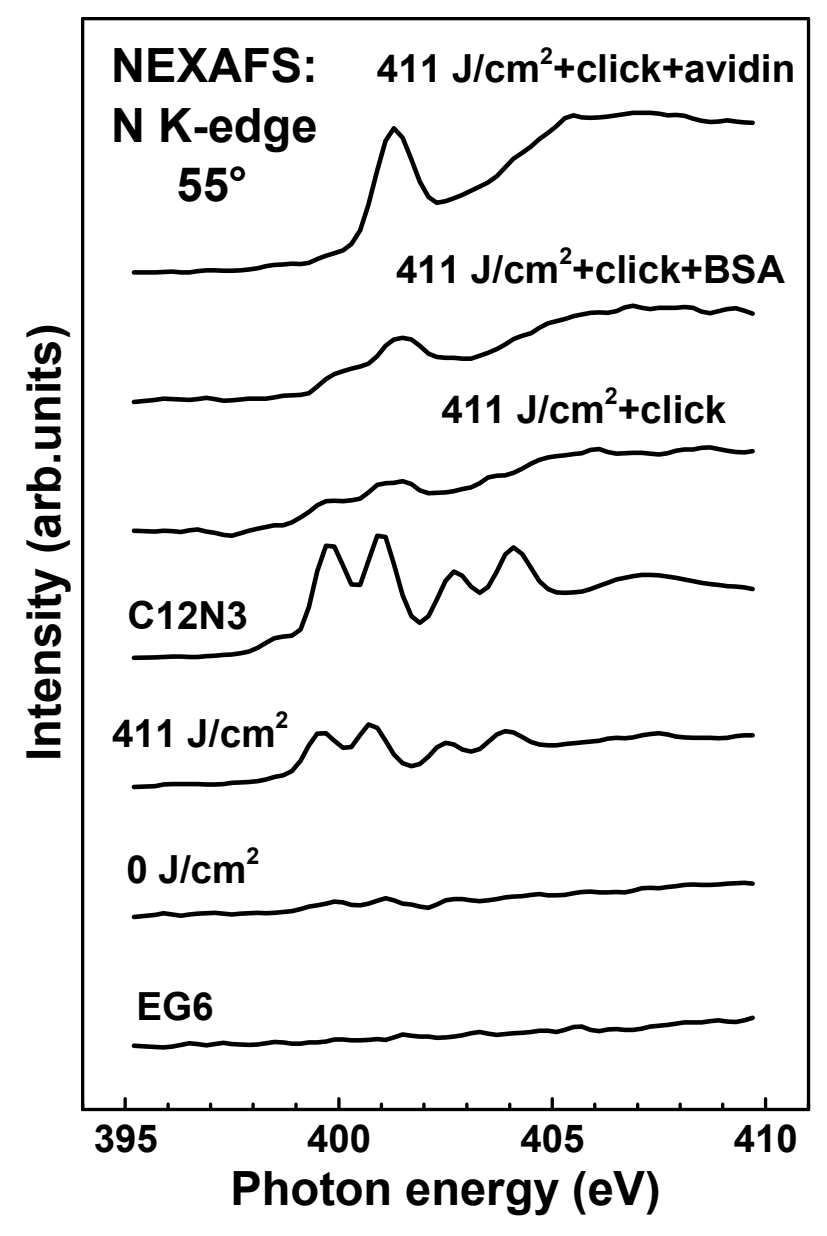

Figure 9 


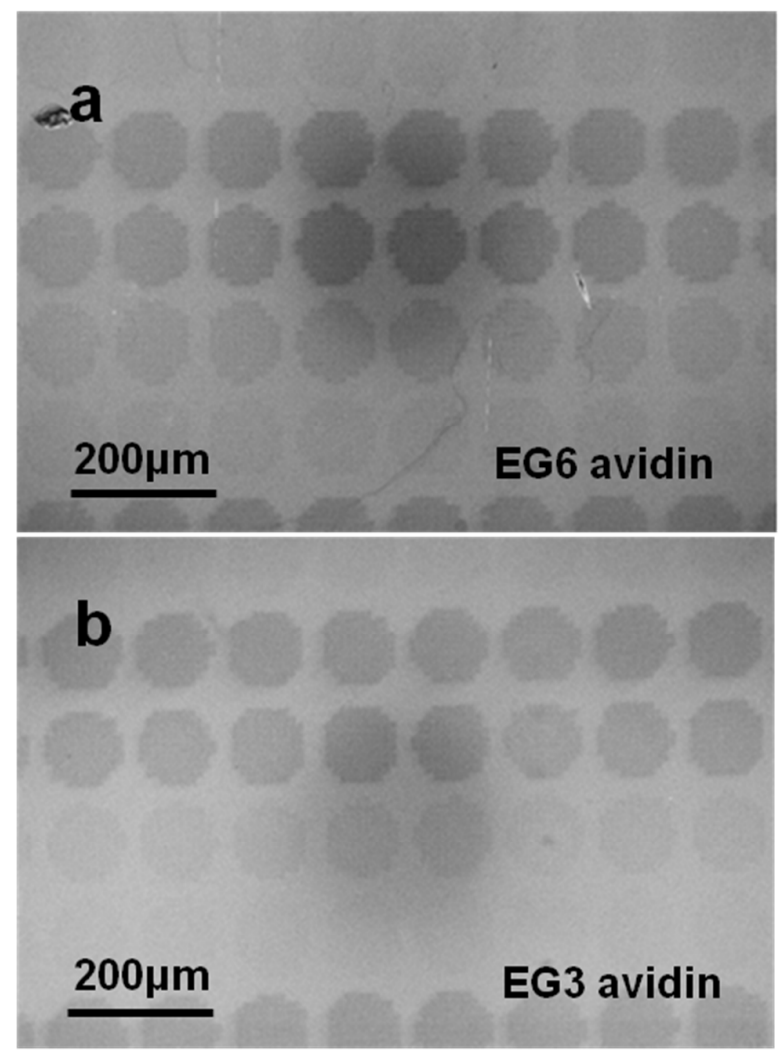

Figure 10 


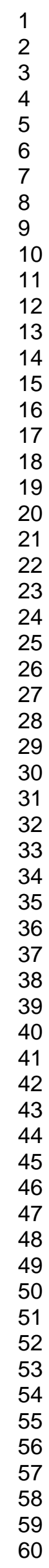

\section{TOC image}

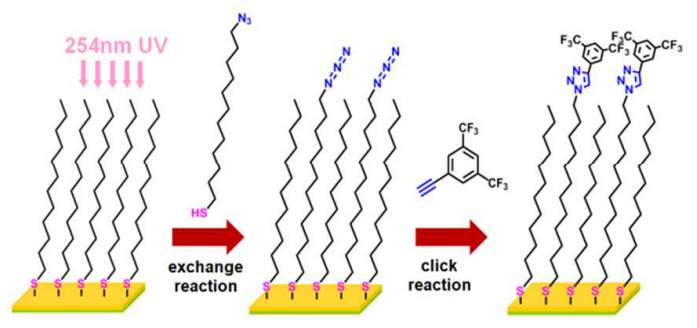

